\title{
Spatio-temporal Dynamics and Transition from Asymptotic Equilibrium to Bounded Oscillations in Chrysomya albiceps (Diptera, Calliphoridae)
}

\author{
Wesley Augusto Conde Godoy $/^{+}$, Fernando José Von Zuben*, \\ Cláudio José Von Zuben**, Sérgio Furtado dos Reis***
}

\begin{abstract}
Departamento de Parasitologia, IB, Universidade Estadual Paulista, Rubião Junior, 18618-000 Botucatu, São Paulo, Brasil *Departamento de Engenharia de Computação e Automação Industrial ***Departamento de Parasitologia, IB,Universidade Estadual de Campinas, Campinas, SP, Brasil **Departamento de Zoologia, IB, Universidade Estadual Paulista, Rio Claro, SP, Brasil
\end{abstract}

The sensitivity of parameters that govern the stability of population size in Chrysomya albiceps and describe its spatial dynamics was evaluated in this study. The dynamics was modeled using a densitydependent model of population growth. Our simulations show that variation in fecundity and mainly in survival has marked effect on the dynamics and indicates the possibility of transitions from one-point equilibrium to bounded oscillations. C. albiceps exhibits a two-point limit cycle, but the introduction of diffusive dispersal induces an evident qualitative shift from two-point limit cycle to a one fixed-point dynamics. Population dynamics of C. albiceps is here compared to dynamics of Cochliomyia macellaria, C. megacephala and C. putoria.

Key words: spatial dynamics - sensitivity analysis - Chrysomya albiceps

The invasion of new habitats by organisms is an important ecological phenomenon since invading species generally have tremendous ecological and economic impact on new areas (Hengeveld 1989, Andow et al. 1993, Kareiva 1996). Biological invasions can take place in different ways including invasions into patchy environments and by stratified diffusion both in short and long-range dispersal (Shigesada \& Kawasaki 1997). The consequences of an invasion may vary from competition for food or space between invading and native species, to invasion of parasites and the spread of epidemic diseases (Hengeveld 1989, Shigesada \& Kawasaki 1997).

Invader populations depend on physical and biological factors for success in invasion and colonization process (Stiling 1996). Among the main biological factors associated to population growth as

\footnotetext{
Research supported by grants from Fundação de Amparo à Pesquisa do Estado de São Paulo (nos. 95/9299-9 and 98/07474-6).

CJVZ, FJVZ and SFR has been supported by research fellowships from Conselho Nacional de Desenvolvimento Científico e Tecnológico.

${ }^{+}$Corresponding author. Fax: +55-14-821.3744. E-mail: wgodoy@ibb.unesp.br

Received 15 August 2000

Accepted 11 January 2001
}

well as success in colonization, persistence and extinction of populations in new areas deserve special attention since the future of the invading species in its new habitat depends basically on the period of time that they stay in the new habitat (Hengeveld 1989, Caughley \& Gunn 1996, Hanski 1998).

The temporal change in the population density of organisms at certain spatio-temporal coordinates can occur as a result of births, deaths, immigration and emigration (Rhodes \& Odum 1996, Hastings 1997). Methodologically it is simpler to study demographic processes only in a temporal context because they are essentially an one-dimensional problem (Turchin 1998). Migration, however, involves two scales - temporal and spatial - rendering its study intrinsically more complex (Schneider 1989). Ecologists have realized that movement is a critical but little understood process affecting population numbers (Ranta et al. 1998). Movement can subtract or add individuals to a population, can alter the outcome of species interactions, provide crucial genetic variability and rescue population from extinction (Kendall \& Fox 1998, Turchin 1998). However, to know whether any of these postulated effects are of practical importance, we need to be able to investigate dispersal.

Around twenty years ago, three species of blowflies originary from Africa and Asia, Chrysomya albiceps, C. megacephala and C. putoria have become established in Brazil (Guimarães et al. 1978, 1979, Baumgartner \& Greenberg 1984). This inva- 
sion has culminated with the sudden decline in population numbers of an ecologically similar species, Cochliomyia macellaria $(\mathrm{F}$.), which is native to the Americas (Greenberg \& Szyska 1984). Some lifehistory aspects of the introduced species can be implied in the displacement of the native species $C$. macellaria, since $C$. albiceps is a species that exhibits a predatory behavior on larvae of other species during the larval stage (Coe 1978, Gagné, 1981, Erzinçlioglu \& Whitcombe 1983, Faria et al. 1999).

This behavior has been studied in details by a choice and no-choice experiment, where there are strong evidences to believe that $C$. albiceps larvae prefer $C$. macellaria larvae instead of $C$. megacephala and C. putoria (Faria et al. 1999). In addition Chrysomya species have shown higher competitive ability than $C$. macellaria in experimental and natural conditions (Wells \& Greenberg 1992a,b,c, Reis et al. 1999). Besides the biological invasion problem, these species are important mechanic vectors of diseases and causers of facultative myiasis in humans and animals (Zumpt 1965, Greenberg 1971, 1973, Baumgartner \& Greenberg 1984, Wells 1991).

We have initiated a research program as an attempt to better understand the blowflies invasion process (Godoy et. al. 1996, 1997, Reis et al. 1996). In this program we have integrated mathematical and biological approaches in order to address questions involving spatio-temporal dynamics. By use of mathematical models of population growth, the dynamic behavior of two invader species, $C$. megacephala and $C$. putoria, and of the native species $C$. macellaria was analyzed and the results indicate that the introduced and native species differ markedly in their equilibrium dynamics (Godoy et al. 1993, 1996, 1997, Von Zuben et al. 1993, Reis et al. 1996, Teixeira et al. 1998). Application of the mathematical model using density-dependent parameters such as fecundity and survival derived from experimental populations showed that C. megacepahala and $C$. putoria exhibit stable oscillations with numbers fluctuating between two points in sucessive generations (Godoy et al. 1993, Von Zuben et al. 1993), whereas in C. macellaria the dynamics is characterized by damping oscillations in population size leading to one fixed point equilibrium (Reis et al. 1996, Godoy et al. 1997).

In this paper we investigate the theoretical dynamics of experimental populations of $C$. albiceps as an attempt to understand its population biology and compare the results obtained with those observed by Reis et al. (1996), Godoy et al. (1997) and Teixeira et al. (1998). We specifically, analyzed the population dynamics of $C$. albiceps by means of a mathematical model that incorporates fecundity and survival as density-dependent demo- graphic parameters in discrete time. We also investigated the sensitivity of these parameters to changes in the magnitude of its values and analyzed the dynamic behavior in a spatial structure based on the coupled lattice maps formalism, in order to investigate if the population dynamics of these species is influenced by spatial migration.

\section{MATERIALS AND METHODS}

Laboratory population of C. albiceps - Specimens of $C$. albiceps were collected in the vicinities of the campus of Universidade Estadual Paulista, Botucatu, São Paulo, Brazil. Adult flies were maintained in laboratory conditions in cages $(30 \times 30 \times 30 \mathrm{~cm})$ covered with nylon at $25 \pm 1^{\circ} \mathrm{C}$ and were fed water and sugar ad libitum. Adult females were fed fresh beef liver to permit the complete development of the gonotrophic cycle (Linhares 1988). The experiment was performed using the generation $\mathrm{F}_{2}$, which is progeny of one generation which had its life cycle completed in the laboratory. Exploitative intraspecific competition among immatures, which is known to occur under natural conditions (de Jong 1976, Lomnicki 1988) was established in the laboratory by setting up six replicated larval densities, developing in $20 \mathrm{~g}$ of ground beef, ranging from 100 to 1,000 larvae per vial at intervals of 200.

This range of densities is suitable to simulate intraspecific competition process in $C$. albiceps since it produces decrease in demographic parameters as a function of density (Godoy et al. 1993, Von Zuben et al. 1993, Reis et al. 1994, 1996). Fecundity was measured counting the number of eggs per female and expressed as the average of daily egg output, which is based on the length of the gonotrophic cycle of Chrysomya species at $25^{\circ} \mathrm{C}$ (Avancini \& Prado 1986, Linhares 1988). Maximum sample size for estimation of fecundity was 30 females per vial. Sample sizes smaller than 30 in some vials were due to either low immature survival rates or incomplete ovarian development. Survival was estimated as the number of adults emerging from each vial.

Mathematical model - The mathematical model developed by Prout and McChesney (1985) was applied to investigate the dynamics of laboratory populations of $C$. albiceps. This model is based on a finite difference equation that models population dynamics considering the number of immatures, eggs or larvae, in succeeding generations, $n_{t+1}$ and $n_{t}$. Prout and McChesney's model incorporates two density-dependent processes, the variation of fecundity and survival as function of density of immatures, $n_{t}$. The recursion is written in the nonlinear finite difference equation 


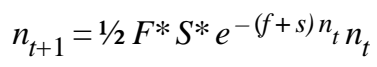

where $F^{*}$ and $S^{*}$ are the intercepts in the regression analysis of fecundity and survival as a function of larval density. These parameters describe the theoretical values for maximum fecundity and survival, respectively. The factor of $1 / 2$ indicates that only half of the population are adult females which contribute with eggs to the next generation. The values of $f$ and $s$ are regression coefficients that estimate the slope of fecundity and survival on the density of immatures. The exponential function was used because it fitted the $C$. albiceps data equal to or better than linear and hyperbolic functions and, the linear regression is known to produce larger slopes in absolute magnitude that produces larger eigenvalues which do not accurately describe the model dynamics at carrying capacity (Mueller 1986). In addition the decrease in fecundity as a function of density of immatures can be viewed biologically as a Poisson process, which is decribed by an exponential function (Rodriguez 1989).

The effect of parameter variation on the population dynamics of $C$. albiceps was investigated through simulations varying maximum fecundity $\left(F^{*}\right)$ and survival $\left(S^{*}\right)$, intercepts in the regression analysis. All simulations were carried out with Matlab (Moler et al. 1987). In the simulations reported here, fecundity was arbitrarily allowed to vary up to a mean daily egg output of 40 eggs (the maximum value of fecundity observed for females of this species; pers. obs.).

Spatial structure was incorporated to equation (1) employing the physical formalism of coupled map lattices (Bascompte \& Solé 1994). The spatial dimension was incorporated as a discrete lattice of points with the populations arranged on the nodes of this square lattice and the population in each node is linked with dispersal to the four nearest neighbors. The spatial structure is incorporated to equation (1) yielding an equation for the spatiotemporal dynamics as

$$
n_{t+1}(i, j)=1 / 2 F^{*} S^{*} e^{-(f+s) n_{t}(i, j)} n_{t}(i, j)+D \nabla^{2} n_{t}(\mathrm{r})
$$

where $D$, is the diffusion rate that indexes dispersal as the fraction of the population that is exchanged in each node, $(i, j)$, and

$$
\nabla^{2} n_{t}(\mathrm{r})=n_{t}(i-1, j)+n_{t}(i+1, j)+n_{t}(i, j-1)+n_{t}(i, j+1)-4 n_{t}(i, j)
$$

defines the geometry of the diffusion between points in the lattice. The term $D \nabla^{2} n_{t}(\mathrm{r})$ gives the diffusion effects which define the individuals that disperse to the adjacent nodes, and those that immigrate from these nodes. Dispersal between nodes, i. e., the local populations, was established in a $3 \mathrm{x}$ 3 lattice yielding a total of nine adjacent nodes. Dispersal occurred by simple diffusion with a fixed fraction of each population migrating to a nearest neighbor each generation. The migration rate $(D)$ was set to 0.2 and both it and the carrying capacity and the migration rate $(D)$ were kept constant throughout generations although varied randomly between adjacent nodes. The spatio-temporal dynamics was simulated using eqn 2 and carried out with MatLab (Moler et al. 1987).

The findings for the temporal and spatial dynamics of $C$. albiceps obtained in this paper are compared and discussed with those obtained for C. megacephala, C. putoria and C. macellaria, which are described in Godoy et al. $(1996,1997)$ and Reis et al. (1996) using the same mathematical formalism.

\section{RESULTS}

Survival and fecundity of $C$. albiceps decreased as function of density of immatures and this decrease was statistically significant (Tables I, II). Slopes of the exponential regression for fecundity and survival were significantly different from zero $(P<0,001)$ (Table II). Theoretical values for maximum fecundity $\left(F^{*}\right)$ and survival $\left(S^{*}\right)$, and the regression coefficients (Table II) describing the dependence of fecundity $(f)$ and survival $(s)$ upon density of immatures were incorporated to equation (4), which can be written as

$$
n_{t+1}=1 / 2\left[\left(27.11 e^{-0.001 n_{t}}\right)\left(0.56 e^{\left.-0.003 n_{t}\right)} n_{t}\right]\right.
$$

The qualitative dynamics of $C$. albiceps can be assessed by the eigenvalue associated with equation (1), which is larger than 1 in modulus $(\lambda=-1.0398)$ and has so two points stable equilibrium.

The dynamic behavior observed for C. albiceps was derived from the application of fixed parameter values to the non-linear difference equation (1). Bifurcation diagrams show that increasing values for fecundity produce qualitative changes in the dynamics of the C. albiceps (Fig. 1) and, for values of fecundity larger than 26 eggs, there is apparently a transition in the dynamics from stable equilibrium to two point limit cycle. When survival is analyzed, the upper limit is 1.0, which represents a theoretical maximum viability of $100 \%$. In this case we can see that the effect of survival on the dynamics of $C$. albiceps is much more noticeable than that of fecundity, since two bifurcations were realized (Fig. 1).

The consequences of diffusive dispersal for the population dynamics of $C$. albiceps are illustrated in Fig. 2. The oscillations in population numbers 
TABLE I

Mean daily fecundity and survival in six larval densities of Chrysomya albiceps

\begin{tabular}{|c|c|c|c|c|c|c|c|c|}
\hline \multirow[b]{2}{*}{ Densities } & \multicolumn{4}{|c|}{$\begin{array}{c}\text { Fecundity } \\
\text { (number of eggs) }\end{array}$} & \multicolumn{4}{|c|}{ Survival (\%) } \\
\hline & $\mathrm{N}$ & $\bar{x}$ & \pm & $\mathrm{Sd}$ & $\mathrm{N}$ & $\bar{x}$ & \pm & $\mathrm{Sd}$ \\
\hline 100 & 25 & 26.46 & \pm & 4.13 & 2 & 54 & \pm & 8.5 \\
\hline 200 & 54 & 21.02 & \pm & 2.96 & 2 & 34 & \pm & 9.5 \\
\hline 400 & 29 & 19.24 & \pm & 2.97 & 2 & 12 & \pm & 11.4 \\
\hline 600 & 17 & 15.91 & \pm & 3.15 & 2 & 7.2 & \pm & 6.8 \\
\hline 800 & 22 & 13.63 & \pm & 2.87 & 2 & 6.9 & \pm & 2.4 \\
\hline 1000 & 10 & 8.57 & \pm & 2.43 & 2 & 2 & \pm & 0 \\
\hline
\end{tabular}

TABLE II

Parameters of regression analysis of fecundity and survival on larval density

\begin{tabular}{lcc}
\hline & Fecundity & Survival \\
\hline Maximum $(F)$ & 27.11 & 0.565 \\
Regression coeficient $(f)$ & $1 \times 10^{-3}$ & $3 \times 10^{-3}$ \\
$t$ value & $18.36^{a}$ & 5.48 \\
$r^{2}$ & 68.5 & 75 \\
$\mathrm{~F}$ & 337 & 30 \\
\hline$a: \mathrm{P}<0.001$ & &
\end{tabular}

as a function of time measured in generations is shown, both for the non-spatial homogeneous model, equation (1), and the spatially structured model, equation (2) (Fig. 2). Our simulations suggest that the linkage between populations introduced by diffusive dispersal produces a qualitative effect on the local dynamics of $C$. albiceps from two point limit cycle to stable equilibrium (Fig. 2). In addition, spatial structure introduced a small quantitative effect in the population dynamics, characterized by the change in the spectrum of the oscillations.

\section{DISCUSSION}

The mathematical analysis performed in this study reveals that $C$. albiceps shows a dynamic behavior represented by a limit cycle of two points, since $\lambda=-1,0398$ (larger than one in module). This behavior was also observed in C. megacephala and C. putoria (Godoy et al. 1993, Von Zuben et al. 1993), but it differs from the native species, $C$. macellaria, that shows damping oscillations in population size leading to one fixed point equilibrium (Reis et al. 1996). We noted, however, that the value of $\lambda$ obtained for $C$. albiceps is very close to one if compared to the other values observed for C. megacephala, $\lambda=-1.3761$ and C. putoria, $\lambda=-1.2399$ (Godoy et al. 1996). This result suggests that $C$. albiceps is a species apparently more susceptible to changes in its dynamic behavior than C. megacephala and C. putoria.
Stability of equilibrium has been extensively investigated in insect populations (Dennis et al. 1995, Costantino et al. 1995, 1997, 1998, Cushing et al. 1998) and perhaps the most important question arising in this context be what governs the transitions from stable to unstable equilibria. The effects produced by the manipulation of the parameter values are well known in theoretical population models (May \& Oster 1976, Edelstein-Keshet 1998) and evidences for such changes come from theoretical and empirical studies (Cavalieri \& Koçak 1995, Costantino et al. 1995, 1997, Denis et al. 1995, 1997). Experiments designed to test prediction of population models have shown that shifts in dynamical behavior can occur, from stable point equilibria, to stable limit cycles, to aperiodic cycles in response to changes in the rate of adult stage mortality (Costantino et al. 1995, 1997, Denis et al. 1995, 1997).

In our study the simulations revealed that the transition from asymptotic stable equilibrium to bounded oscillations occurs with an increase in fecundity and survival. It is interesting to note that the results of this study indicate a more frequent variation of dynamic behavior when the survival values are manipulated. Recently, Godoy et al. (1996) used the same technique to analyse the transition of dynamic behavior in C. megacephala, $C$. putoria and C. macellaria and observed that the effect of survival on the dynamics of these species is much less noticeable than of fecundity, since no more than one bifurcation was obtained in the three species studied (Fig. 1). Fecundity was shown in the simulations to be the most important demographic parameter to bring about shifts in the dynamic behavior of experimental populations of $C$. megacephala, C. putoria and C. macellaria (Godoy et al. 1996).

The coupled map lattices suggest that the linkage between populations introduced by diffusive dispersal produces a qualitative effect on the local dynamics of $C$. albiceps from two point limit cycle to stable equilibrium (Fig. 2). These results con- 

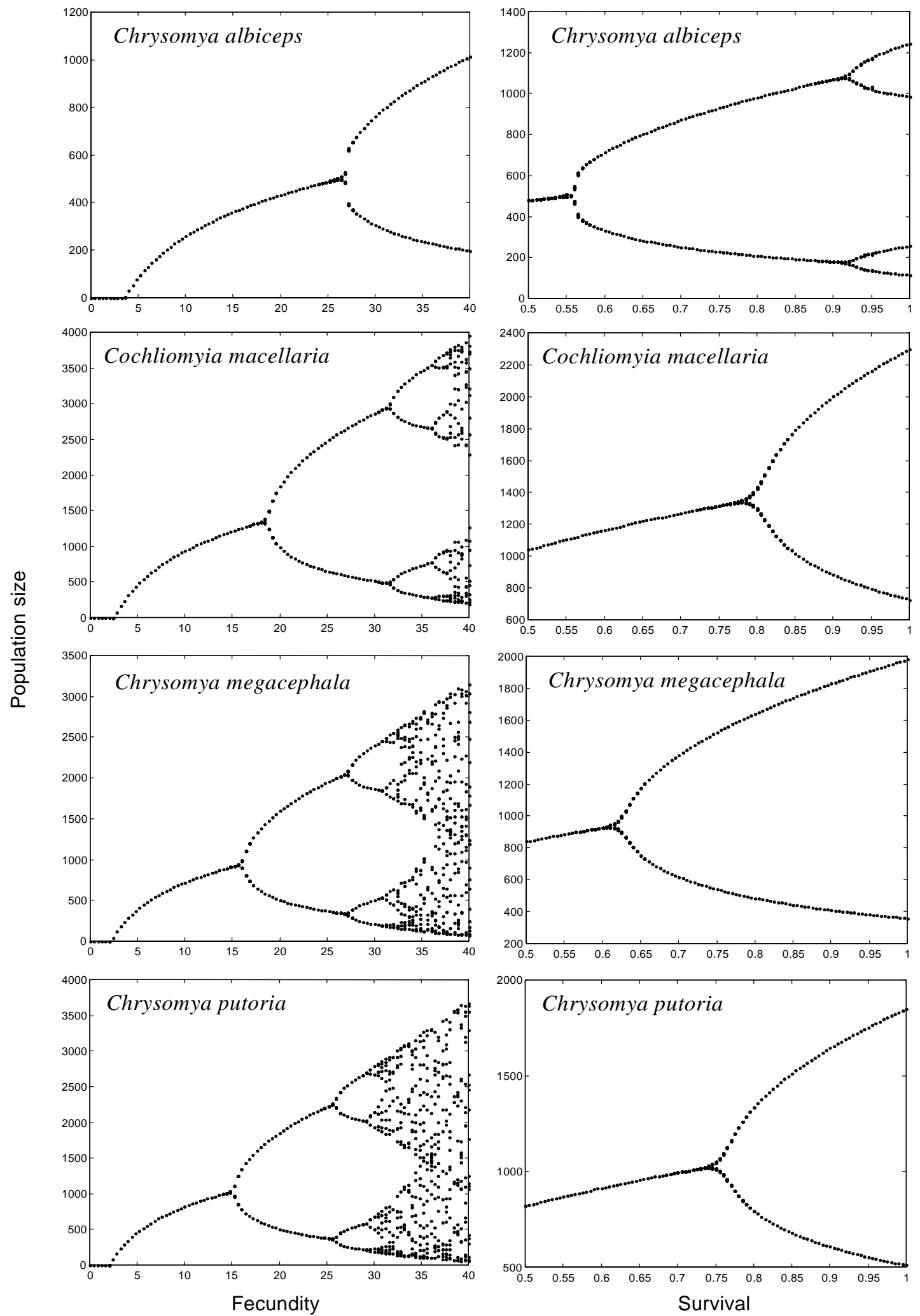

Fig. 1: bifurcation diagrams for stable population sizes as a function of the variation in fecundity and survival for Chrysomya albiceps, Cochliomyia macellaria, C. megacephala and C. putoria. 
firm the findings by Godoy et al. (1997) which revealed that the linkage between populations introduced by diffusive dispersal may produce qualitative and quantitative effects on the local dynamics of C. megacephala, C. putoria and C. macellaria (Fig. 2).

The dynamics system in which $C$. albiceps is inserted gives a wide range of interesting questions since it apparently balances between stability and periodic behavior. This apparent ambiguity as a function of both the parametric manipulation and the spatial structure introduced in the model, places C. albiceps between $C$. macellaria, the native species that exhibits stable dynamics and the other introduced species, C. megacephala and C. putoria, that show two point limit cycle (Reis et al. 1996). We consider this point interesting because in this sense $C$. albiceps is a species that shows a dynamic behavior more susceptible to changes than $C$. megacephala and C. putoria. We do not know if this characteristic is advantageous to $C$. albiceps, however it has proved to be a species with conspicuous abilities under competitive stress, what probably have influenced negatively the structure of the community where it lives (Ullyett 1950, Coe 1978, Faria et al. 1999).

The spread of invading organisms is the outcome of complex interactions involving the dynamics of populations at temporal and spatial scales (Hengeveld 1989). The importance of the spatial component has always been recognized (Lewis \& Kareiva 1993), although recently a stronger emphasis has been placed on spatial structure as result of theoretical developments that have established a correlation between migration and dynamic behavior of populations (Comins et al. 1992, Allen et al. 1993, Hastings 1993, Bascompte \& Solé 1995, Ruxton 1995, Kendall \& Fox 1998). The results found in these investigations show two opposite ways, on the one hand the complex or chaotic temporal dynamics can be induced by the presence of the spatial dimension (Comins et al. 1992,
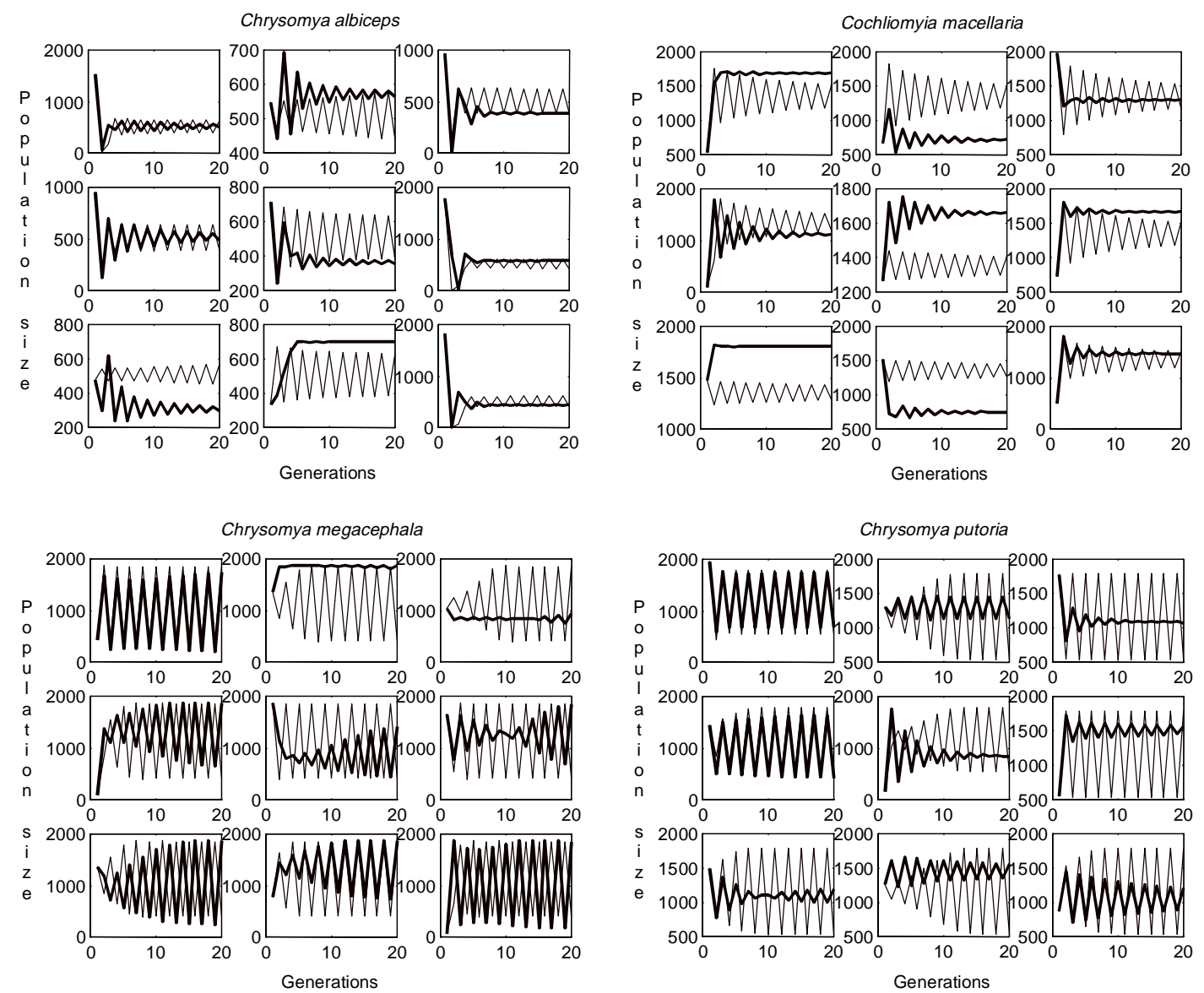

Fig. 2: evolution of population size across generations obtained from the non-spatial, homogeneous model (draft line) given by equation (1), and the spatially structured model (bold line) given by equation (2). 
Pascual 1993) and on the other hand, simple periodic dynamics may be induced by the presence of the diffusive dispersal (Hastings 1993, Csilling et al. 1994). Our simulations indicate that the spatial dimension induces an overall stabilizing effect on the dynamics of $C$. albiceps. This paper, together with the previous focus the connection between population dynamics and the invasion of blowflies (Reis et al. 1996, Godoy et al. 1996, 1997), seem to confirm the findings of Costantino et al. (1995, 1997) and Allen et al. (1993), which have taken together a new conceptual thread connecting sensitivity to demographic changes, qualitative changes in dynamic behavior and extinction rates. In addition, the peculiar characteristics found in C. albiceps, which seem to have implications to population dynamics, open a series of new perspectives for studies of equilibrium dynamics.

\section{ACKNOWLEDGMENTS}

To the anonymous reviewer for making suggestions that improved the clarity of the manuscript.

\section{REFERENCES}

Allen JC, Schaeffer WM, Rosko D 1993. Chaos reduces species extinction by amplifying local population noise. Nature 364: 229-232.

Andow DA, Kareiva PM, Levin SA, Okubo A 1993. Spread of invading organisms: patterns of spread. In KC Kim, BA Mcpheron (eds), Evolution of Insect Pests. Patterns of Variation, John Wiley, New York, p. 219-242.

Avancini RMP, Prado AP 1986. Oogenesis in Chrysomya putoria (Wiedemann) (Diptera: Calliphoridae). Int J Ins Morph Emb 15: 375-384.

Bascompte J, Solé RV 1994. Spatially induced bifurcations in single-species population dynamics. J Anim Ecol 63: 256-264.

Bascompte J, Solé RV 1995. Appropriate formulations for dispersal in spatially structured models: reply. $J$ Anim Ecol 64: 665-666.

Baumgartner DL, Greenberg B 1984. The genus Chrysomya (Diptera: Calliphoridae) in the New World. $J$ Med Ent 21: 105-113.

Caughley G, Gunn A 1996. Conservation Biology in Theory and Practice, Blackwell Science, Cambridge, Massachusetts, $458 \mathrm{pp}$.

Cavalieri LF, Koçak H 1995. Intermittent transition between order and chaos in an insect pest population. $J$ Theor Biol 175: 231-234.

Coe RL 1978. The decomposition of elephant carcases in the Tsavo (East) National, Kenya. J Arid Env 1: 71-86.

Comins HN, Hassell MP, May RM 1992. The spatial dynamics of host-parasitoid systems. J Anim Ecol 61: 735-748.

Costantino RF, Cushing JM, Dennis B, Desharnais RA 1995. Experimentally induced transitions in the dynamic behaviour of insect populations. Nature 375: 227-230.
Costantino RF, Cushing JM, Dennis B, Desharnais RA, Henson SM 1998. Resonant population cycles in temporally fluctuating habitats. Bull Math Biol 60: 247-273.

Costantino RF, Desharnais RA, Cushing JM, Dennis B 1997. Chaotic dynamics in an insect population. Science 275: 389-391.

Csiling AI, Jánosi M, Pastor G, Scheuring I 1994. Absence of chaos in a self-organized critical coupled map lattice. Phys Rev E 50: 1083-10092.

Cushing JM, Costantino RF, Dennis B, Desharnais RA, Henson SM 1998. Nonlinear population dynamics: models, experiments and data. J Theor Biol 194: 19.

Dennis B, Desharnais RA, Cushing JM, Costantino RF 1995. Nonlinear demographic dynamic dynamics: mathematical model, statistical methods and biological experiments. Ecol Monog 65: 261-281.

Dennis B, Desharnais RA, Cushing JM, Costantino RF 1997. Transitions in population dynamics: equilibria to periodic cycles to aperiodic cycles. J Anim Ecol 66: 704-729.

de Jong G 1976. A model of competition for food. I. Frequency-dependent variabilities. Am Nat 110: 1013-1027.

Edelstein-Keshet L 1988. Mathematical Models in Biology, Random House, New York, 586 pp.

Erzinçlioglu YZ, Whitcombe RP 1983. Chrysomya albiceps (Wiedemann) (Dipt., Calliphoridae) in dung and causing myiasis in Oman. Ent Mont Mag 119: 51-52.

Faria LDB, Orsi L, Trinca LA, Godoy WAC 1999. Larval predation by Chrysomya albiceps on Cochliomyia macellaria, Chrysomya megacephala and Chrysomya putoria. Ent Exp App 90: 149-155.

Gagné RJ 1981. Chrysomya spp., old world blowflies (Diptera, Calliphoridae), recently established in the Americas. Bull Ent Soc Am 27: 21-22.

Godoy WAC, Reis SF, Von Zuben CJ, Ribeiro OB 1993. Population dynamics of Chrysomya putoria (Wied.) (Dipt., Calliphoridae). J App Ent 116: 163-169.

Godoy WAC, Von Zuben CJ, Reis SF, Von Zuben FJ 1996. Dynamics of experimental populations of native and introduced blowflies (Diptera: Calliphoridae): mathematical modelling and the transition from asymptotic equilibrium to bounded oscillations. Mem Inst Oswaldo Cruz 91: 641-648.

Godoy WAC, Von Zuben CJ, Reis SF, Von Zuben FJ 1997. The spatial dynamics of native and introduced blowflies (Dipt., Calliphoridae). J App Ent 121: 305309.

Greenberg B, 1971. Flies and Disease, Vol. 1, Princeton University Press, Princeton, 865 pp.

Greenberg B, 1973. Flies and Disease, vol. 2, Princeton University Press, Princeton, 447 pp.

Greenberg, B, Szyska ML 1984. Immature stages and biology of fifteen species of peruvian Calliphoridae (Diptera). Ann Ent Soc Am 77: 488-517.

Guimarães JH, Prado AP, Linhares AX 1978. Three newly introduced blowfly species in Southern Brazil (Diptera: Calliphoridae). Rev Bras Ent 22: 5360. 
Guimarães JH, Prado AP, Buralli GM 1979. Dispersal and distribution of thre e newly introduced species of Chrysomya Robineau-Desvoidy in Brazil (Diptera, Calliphoridae). Rev Bras Ent 23: 245-255.

Hanski I 1998. Connecting the parameters of local extinction and metapopulation dynamics. Oikos 83: 390-396.

Hastings A 1993. Complex interactions between dispersal and dynamics: lessons from coupled logistic equations. Ecology 74: 1362-1372.

Hastings A 1997. Population Biology. Concepts and Models, Springer-Verlag, New York, 220 pp.

Hastings A, Costantino RF 1987. Cannibalistic egg-larva interactions in Tribolium: an explanation for the oscillations in population numbers. Am Nat 120: 36-52.

Hengeveld R 1989. Dynamics of Biological Invasions, Chapman and Hall, NY, 160 pp.

Kareiva P 1996. Developing a predictive ecology for non-indigenous species and ecological invasions. Ecology 77: 1651-1652.

Kendall BE, Fox GA 1998. Spatial structure, environmental heterogeneity and population dynamics: analysis of the coupled logistic map. Theor Pop Biol 54: 11-37.

Lewis MA, Kareiva P 1993. Allee dynamics and the spread of invading organims. Theor Pop Biol 43: 141-158.

Linhares AX 1988. The gonotrophic cycle of Chrysomya megacephala (Diptera: Calliphoridae) in the laboratory. Rev Bras Ent 32: 383-392.

Lomnicki A 1988. Population Ecology of Individuals, Princeton University Press, Princeton, 223 pp.

May RM, Oster GF 1976. Bifurcations and dynamic complexity in simple ecological models. Am Nat 110: 573-599.

Moler C, Little J, Baugert S 1987. PC-MATLAB User's Guide, version 3.2-PC, The Mathworks, Inc. Sherborn.

Mueller LD 1986. Density-dependent rates of population growth-estimation in laboratory populations. Am Nat 128: 282-293.

Pascual M 1993. Diffusion-induced chaos in a spatial predator-prey system. Philosophical Trans $R$ Soc Lond B251: 1-7.

Prout T, McChesney F 1985. Competition among immatures affects their adult fertility: population dynamics. Am Nat 126: 521-558.

Ranta E, Kaitala V, Lundberg P 1998. Population variability in space and time: the dynamics of synchronous population fluctuations. Oikos 83: 376-382.

Reis SF, Stangenhaus G, Godoy WAC, Von Zuben CJ, Ribeiro OB 1994. Variação em caracteres bionômicos em função da densidade larval em Chrysomya megacephala e Chrysomya putoria (Diptera, Calliphoridae). Rev Bras Ent 38: 33-46.

Reis SF, Teixeira MA, Von Zuben FJ, Godoy WAC, Von Zuben CJ 1996. Theoretical dynamics of experimental populations of introduced and native blowflies (Diptera, Calliphoridae). J Med Ent 33: 537-544.
Reis SF, Von Zuben CJ, Godoy WAC 1999. Larval aggregation for food in experimental population of Chrysomya putoria (Wied.) and Cochliomyia macellaria (F.) (Dipt. Calliphoridae). J App Ent 123: 485-489.

Rhodes Jr OE, Odum EP 1996. Spatio-temporal approaches in ecology and genetics: the road less traveled. In OD Rhodes Jr, RK Chesser, MH Smith (eds), Population Dynamics in Ecological Space and Time, The University of Chicago Press, Chicago, p. 1-7.

Rodriguez DJ 1989. A model of population dynamics for the fruit fly Drosophila melanogaster with density dependence in more than one life stage and delayed density effects. J Anim Ecol 58: 349-365.

Ruxton GD 1995. Temporal scales and the occurrence of chaos in coupled populations. TREE 10: 141-142.

Schneider JC 1989. Role of movement in evaluation of area-wide insect pest management tatics. Env Ent 18: 868-874.

Shigesada N, Kawasaki K 1997. Biological Invasions: Theory and Practice, Oxford University Press, Oxford, $205 \mathrm{pp}$.

Stiling PD 1996. Ecology Theories and Applications, Prentice Hall, NJ, 538 pp.

Teixeira MA, Von Zuben FJ, Godoy WAC, Von Zuben CJ, Reis SF 1998. Delayed density dependence at the immature stage in insects and the dynamic behavior of nonlinear difference equations. Cien Cult 48: 268-272.

Turchin P 1998. Quantitative Analysis of Movement: Measuring and Modeling Population Redistribution in Animals and Plants, Sinauer Associates, Inc. Publishers, Sunderland, 396 pp.

Ulllyett GC 1950. Competition for food and allied phenomena in sheep-blowfly population. Phil Trans $R$ Soc Lond B334: 77-174.

Von Zuben CJ, Reis SF, do Val JBR, Godoy WAC, Ribeiro OB 1993. Dynamics of a mathematical model of Chrysomya megacephala (Diptera: Calliphoridae). J Med Ent 30: 443-448.

Wells JD 1991. Chrysomya megacephala (Diptera: Calliphoridae) has reached the continental United States: review of its biology, pest status, and spread around the world. J Med Ent 28: 471-473.

Wells JD, Greenberg B 1992a. Rates of predation by Chrysomya rufifacies (Macquart) on Cochliomyia macellaria (Fabr.) (Diptera: Calliphoridae) in the laboratory: effect of predator and prey development. Pan-Pac Ent 68: 12-14.

Wells JD, Greenberg B 1992b. Laboratory interaction between introduced Chrysomya rufifacies and native Cochliomyia macellaria (Diptera: Calliphoridae). Env Ent 21: 640-645.

Wells JD, Greenberg B 1992c. Interaction between Chrysomya rufifacies and Cochliomyia macellaria (Diptera: Calliphoridae): the possible consequences of an invasion. Bull Ent Res 82: 133-137.

Zumpt 1965. Myiasis in Man and Animals in the Old World, Butterworths, London, 267 pp. 